
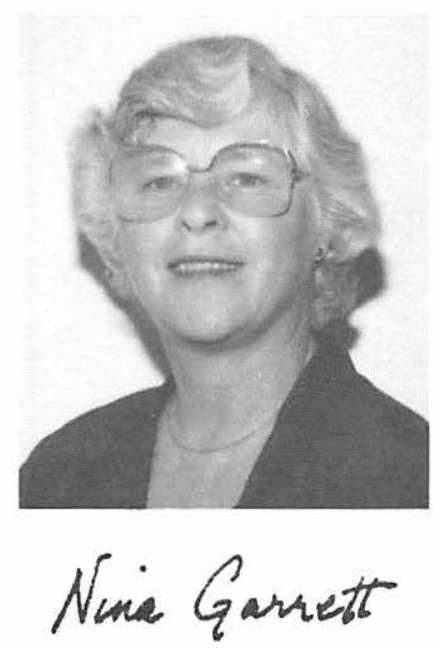

\section{IALL: Many Voices \\ Nina Garrett Yale University}

As many of you know, I'm relatively talkative. I often talk too much, or too fast, or I focus too much about the "big picture." I find myself wondering, therefore, why writing this column tends to be so difficult for me. I think it's because I feel a lot of diffidence about "speaking for" an organization whose membership represents such a rich diversity of talents, experience, expertise. We are as individuals active in such a range of institutions - public, private, large, small, rich, poor, at all levels of education. We bring to our work, and to IALL, such an interesting variety of educational backgrounds, of professional and life experiences, of opinions and goals and passions. I wonder, in fact, whether there are many professional organizations with anything like this diversity of experience-which makes all the more wonderful the pervasive warmth and sharing and fellowship that has always been such a hallmark of IALL!

My point is that no one person, no president or series of presidents, can really represent, or speak for, IALL-which is why it's so important that you as individuals speak up and assert your perspectives on our profession, that you take seriously the value to IALL, to all of us, of your representing those diverse constituencies, commitments, and concerns. Too many of us lurk on LLTI instead of posting to it - perhaps you could be posting queries as well as responding to them, opening up discussions. Too few of us think of writing for this Journal. Lack of time, I know-but perhaps you undervalue the usefulness of your experience to the many newcomers to this field. Or-if you're a newcomer yourself, perhaps you undervalue the usefulness of fresh perspectives, of challenges to assumptions about the field. You can be sure that if you take language technology seriously enough to be a member of IALL, to read this Journal, then your opinions on our profession are worth hearing! 


\title{
CALICO '99
}

Advancing Language Learning Technology into the New Millenium

16th Annual Symposium

Hosted by: Miami University

\section{June 1-5, 1999}

\section{Registration}

June 1 - June 2: Preconference Workshops

June 3: Courseware Fair

June 3- June 5: Regular Presentation Sessions,

Vemdor Exhibits, IALL Sessions, EuroCALL

Sessions, Luncheon, Banquet, Keynote Speakers

\author{
register on-line at: \\ http://www.calico.org \\ or contact: \\ Esther Callais, Coordinator \\ 214 Centennial Hall phone: 512/245-1417
}

601 University Drive fax: $512 / 245-9089$

San Marcos, TX 78666 email: info@calico.org

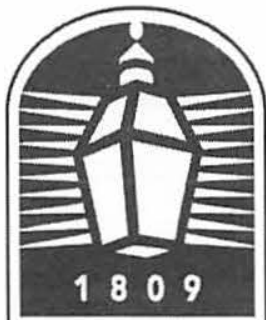

MIAMI
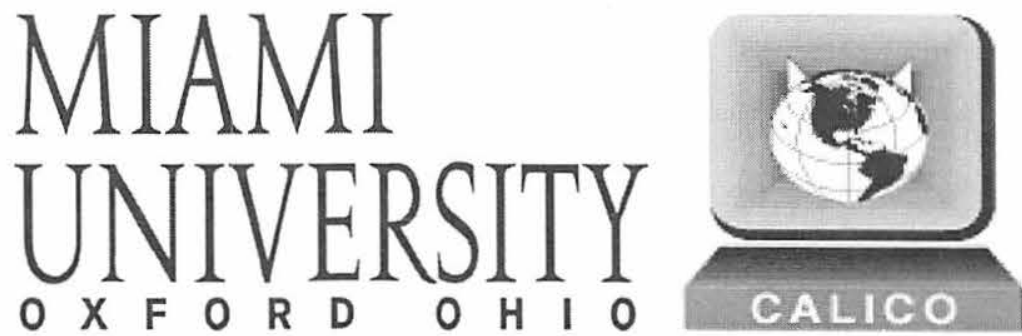